\title{
Bet v 2 Responsibility in Birch-Induced Symptoms
}

\author{
Metz Favre $\mathrm{C}^{1 *}$, Pauli $\mathbf{G}^{1}$, Castro $\mathrm{L}^{2}$, Valenta $\mathrm{R}^{3}$ and de Blay $\mathrm{F}^{1}$
}

${ }^{1}$ Division of Asthma and Immuno-Allergology, Department of Chest Diseases University Hospital, France

${ }^{2}$ Department of Biochemistry and Molecular Biology, University of Complutense, Spain

${ }^{3}$ Department of Pathophysiology, Division of Immunopathology, Center for Physiology and Pathophysiology, Austria

\begin{abstract}
We report the case of a patient who first had grass pollinosis associated to food allergy, especially melon, and who developed secondarily early spring pollinosis which could be related to sensitization to the birch profilin. This patient, whose birch pollinosis was confirmed by nasal provocation test, was not sensitized to Bet $v 1$, the major birch pollen allergen in North Western Europe. We demonstrated by inhibition studies using grass and birch profilins that the clinical birch allergy was induced by the cross reacting profilin present both in birch and grass pollen and also in melon.
\end{abstract}

Keywords: Bet v 2; Birch pollinosis; Profilin

\section{Introduction}

Plant profilins are minor allergens, recognized by about $20 \%$ of pollen allergic patients and can be responsible for cross reactivity among botanically unrelated pollens but also between vegetables and pollens [1]. In birch pollinosis Bet $\mathrm{v} 1$ is considered as a marker [2], in contrast to Bet $v 2$, the birch profilin [3]. Clinical relevance of profilin as a respiratory allergen has been questioned [4]. We report the case of a patient allergic to grass pollen and to melon, which developed secondarily early spring pollinosis which could be related to sensitization to Bet $\mathrm{v} 2$

\section{Case Report}

M.R RS, a 54- year man, living in the North-East of France, has suffered from grass pollinosis for 13 years. He was desensitized with grass pollen extract for 4 years. In the third year he also reported symptoms occurring mid April. In this area fagale pollens flower until mid April and the grass pollen season occurs mid May. He complained of oral syndrome and lip angio-oedema when eating melon for ten years and more recently when eating longane and avocado.

The cutaneous tests were positive to grass (mean weal diameter: $7 \mathrm{~mm})$, to birch $(3 \mathrm{~mm})$, ash pollen $(7,5 \mathrm{~mm})$, artemisia, plantago, solidago, and plane tree $(4 \mathrm{~mm})$. Cutaneous tests with fresh food were positive for melon, longane and avocado $(6 \mathrm{~mm})$. Tests with indoor environment allergens were negative.

Immunological investigations (immuno-CAP Phadia, Uppsala, Sweden) were performed with recombinant allergens. For grass we observed positivity to $\mathrm{rPhl} \mathrm{p} \mathrm{1:} \mathrm{9,59} \mathrm{kU/l,} \mathrm{to} \mathrm{rPhl} \mathrm{p} \mathrm{5:} \mathrm{17,30} \mathrm{kU/l,} \mathrm{to} \mathrm{rPhl}$ p 2: 4,35 kU/l, to $\mathrm{rPhl}$ p 12: 1,57 kU/l; for birch: positivity to Bet $\mathrm{v} 2$ : $1,41 \mathrm{kU} / \mathrm{l}$, negative results were found for $\mathrm{rBet} \mathrm{v} 1$, rBet $\mathrm{v} 4$ and $\mathrm{rBet} \mathrm{v} 6$.

In order to confirm the clinical relevance of this monosensitization to Bet $\mathrm{v} 2$, we performed nasal provocation tests with birch extract (Stallergènes, Antony, France). The patient reacted positively at $10 \mathrm{IR}$, with a clinical score of 4 out of 8 . Symptoms increased with the ten-fold extract concentration.

ELISA inhibition tests were performed with recombinant grass and birch profilins. IgE binding to Bet $\mathrm{v} 2$ were inhibited after preincubation with grass profilin (100\% reduction) whereas IgE binding to $\mathrm{Phl} \mathrm{p} 12$ were inhibited with birch profilin at a lower level of $80 \%$. Two different concentrations of the inhibitor were used $(0.5$ and $1 \mu \mathrm{g} / \mathrm{ml})$ (Figure 1$)$.

\section{Discussion}

By measuring specific IgE to molecular allergens we could confirmed that the patient was sensitized to the major allergens from grass ( $\mathrm{Phl} \mathrm{p} \mathrm{1,} \mathrm{Phl} \mathrm{p} \mathrm{5).} \mathrm{The} \mathrm{positive} \mathrm{nasal} \mathrm{challenge} \mathrm{test} \mathrm{to} \mathrm{birch} \mathrm{extract}$ in our patient monosensitized to Bet $\mathrm{v} 2$ is an argument for the clinical relevance of birch profilin in early spring respiratory symptoms. Crosselectrophoresis of this extract performed with a pool of sera of birch sensitized patients showed immunostaining at $20 \mathrm{kDa}$ corresponding to Bet $\mathrm{v} 1$ and slight immunostaining at $14 \mathrm{kDa}$, suggesting the presence of profilin in the extract (data not shown). The potency of birch profilin to induce respiratory symptoms has been demonstrated by nasal and bronchial challenge tests [5]. The food allergy to melon, suggests profilin sensitization, before grass pollen immunotherapy was introduced. Cuc $\mathrm{m} 2$, the melon profilin was identified as a major allergen recognized by over $70 \%$ of melon allergic patients [6]. The important inhibition of Bet $\mathrm{v} 2$ and $\mathrm{Phl} \mathrm{p} 12$ specific IgE by the two profilins is linked to a great extent of cross reactivity between these 2 allergens. Radauer et al. [7] found in 10 out of 13 patients sensitized to birch profilin that pre-incubation with Bet $\mathrm{v} 2$ inhibited IgE binding to $\mathrm{Phl} \mathrm{p} 12$ by more than $80 \%$. In our case, reciprocal inhibition experiments suggest that the affinity of the IgEs to grass profilin seems to be better than to birch profilin, suggesting primary sensitization by grass pollen profilin $(100 \%$ inhibition with grass profilin and $80 \%$ with birch profilin).

Birch sensitization is rarely linked in our region to monosensitization to Bet $\mathrm{v} 2$. In a previous study [3] only 3 out of 51 patients sensitized to birch recognized Bet $\mathrm{v} 2$ alone and none had symptoms during birch pollen season. This case is in favour of extended sensitization induced by cross-reactive profilins to a clinical pollinosis. By characterization of a principal epitope of the melon profilin Cuc $\mathrm{m} 2$, it was shown that the same consensus sequence was also localized in the birch and grass

*Corresponding author: Favre Metz Carine, Division of Asthma and ImmunoAllergology, Department of Chest Diseases University Hospital, Strasbourg France, Tel: 33 369550904; E-mail: Carine.FAVRE@chru-strasbourg.fr

Received February 20, 2014; Accepted March 25, 2014; Published March 30 2014

Citation: Metz Favre C, Pauli G, Castro L, Valenta R, de Blay F (2014) Bet v 2 Responsibility in Birch-Induced Symptoms. J Allergy Ther 5: 169. doi:10.4172/2155 6121.1000169

Copyright: (c) 2014 Metz Favre C, et al. This is an open-access article distributed under the terms of the Creative Commons Attribution License, which permits unrestricted use, distribution, and reproduction in any medium, provided the original author and source are credited. 


$$
\% \text { inhibition }=\frac{\mathrm{DO}_{\mathrm{BO}}-\mathrm{D}_{\mathrm{OP}}}{\mathrm{DO} \mathrm{BO}_{\mathrm{BO}}-\mathrm{DO}_{\mathrm{NSB}}}
$$

$\mathrm{DO}_{\mathrm{BO}}$ : optical density serum $\mathrm{DO}_{\mathrm{p}}$ : optical density serum + inhobitor $\mathrm{DO}_{\mathrm{NSB}}$ : optical density non specific binding

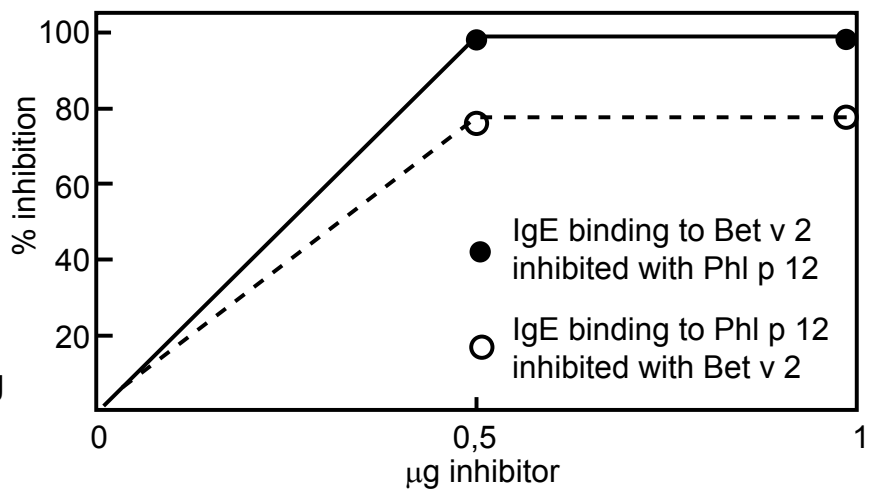

Figure 1: Reciprocal inhibition experiments with birch and grass profilins.

profilins [8]. As the convincing clinical history of allergic reaction to melon occurred before the beginning of grass hyposensitization, this treatment seems not responsible for sensitization to profilin.

In conclusion this case report is in favor of the clinical relevance of profilin as a respiratory allergen. Grass pollen containing a high concentration of profilin [5], grass pollinosis may be the inducer of sensitization to this panallergen and could be a risk factor for other pollinosis in which profilin is the relevant allergen.

\section{References}

1. Valenta R, Duchene M, Ebner C, Valent P, Sillaber C, et al. (1992) Profilins constitute a novel family of functional plant pan-allergens. J Exp Med 175: 377 385

2. Metz-Favre C, Birba E, Metivier A-C, de Blay F, Pauli G (2005) Interêt du dosage des IgE vis-à-vis de l'allergène recombinant rBet $v 1$ dans la prise en charge de la pollinose printanière. Rev Fr Allergol 45: 584-589.

3. Pauli G, Oster JP, Deviller P, Heiss S, Bessot JC, et al. (1996) Skin testing with recombinant allergens $\mathrm{rBet} v 1$ and birch profilin, $\mathrm{rBet} v 2$ : diagnostic value for birch pollen and associated allergies. J Allergy Clin Immunol 97: 1100-1109.

4. Wensing $\mathrm{M}$, Akkerdaas $\mathrm{JH}$, van Leeuwen WA, Stapel SO, Bruijnzeel-Koomen $C A$, et al. (2002) IgE to Bet $v 1$ and profilin: cross-reactivity patterns and clinical relevance. J Allergy Clin Immunol 110: 435-442.

5. Ruiz-García M, García Del Potro M, Fernández-Nieto M, Barber D, JimenoNogales L, et al. (2011) Profilin: a relevant aeroallergen? J Allergy Clin Immunol 128: 416-418.

6. López-Torrejón G, Crespo JF, Sánchez-Monge R, Sánchez-Jiménez $M$ Alvarez J, et al. (2005) Allergenic reactivity of the melon profilin Cuc $\mathrm{m} 2$ and its identification as major allergen. Clin Exp Allergy 35: 1065-1072.

7. Radauer $\mathrm{C}$, Willerroider $\mathrm{M}$, Fuchs $\mathrm{H}$, Hoffmann-Sommergruber $\mathrm{K}$, Thalhamer $\mathrm{J}$ et al. (2006) Cross-reactive and species-specific immunoglobulin E epitopes of plant profilins: an experimental and structure-based analysis. Clin Exp Allergy 36: $920-929$.

8. Tordesillas L, Pacios LF, Palacín A, Cuesta-Herranz J, Madero M, et al. (2010) Characterization of IgE epitopes of Cuc $m$ 2, the major melon allergen, and their role in cross-reactivity with pollen profilins. Clin Exp Allergy 40: 174-181.

This article was originally published in a special issue, Food Allergy handled

by Editor. Dr. Glover Sarah Camille, University of Florida, USA. 